\title{
Increased Health Information Technology Adoption and Use Among Small Primary Care Physician Practices Over Time: A National Cohort Study
}

Diane R. Rittenbouse, $M D, M P H^{1,2}$

Patricia P. Ramsay, MPH

Lawrence P. Casalino, $M D, P b D^{4}$

Sean McClellan, $P b D^{5}$

Zosha K. Kandel, BA ${ }^{3}$

Stephen M. Shortell, PbD, MPH, $\mathrm{MBA}^{3,6}$

'Department of Family and Community Medicine, University of California, San Francisco, California

${ }^{2}$ Philip R. Lee Institute for Health Policy Studies, University of California, San Francisco, California

${ }^{3}$ School of Public Health, University of California, Berkeley, California

${ }^{4}$ Division of Health Policy and Economics, Department of Healthcare Policy and Research, Weill Cornell Medical College, New York, New York

${ }^{5}$ American Institutes for Research, Washington, DC

${ }^{6}$ Haas School of Business, University of California, Berkeley, California

Conflicts of interest: authors report none.

\section{CORRESPONDING AUTHOR}

Diane R. Rittenhouse, MD, MPH Department of Family and Community Medicine and Philip R. Lee Institute for Health Policy Studies

University of California, San Francisco 500 Parnassus Ave, MU308-E

San Francisco, CA 94131

Diane.Rittenhouse@ucsf.edu

\begin{abstract}
PURPOSE Implementation and meaningful use of health information technology (HIT) has been shown to facilitate delivery system transformation, yet implementation is far from universal. This study examined correlates of greater HIT implementation over time among a national cohort of small primary care practices in the United States.
\end{abstract}

METHODS We used data from a 40-minute telephone panel survey of 566 small primary care practices having 8 or fewer physicians to investigate adoption and use of HIT in 2007-2010 and 2012-2013. We used generalized estimating equations (GEE) to estimate the association of practice characteristics and external incentives with the adoption and use of HIT. We studied 18 measures of HIT functionalities, including record keeping, clinical decision support, patient communication, and health information exchange with hospitals and pharmacies.

RESULTS Overall, use of 16 HIT functionalities increased significantly over time, whereas use of 2 decreased significantly. On average, compared with physicianowned practices, hospital-owned practices used 1.48 (95\% Cl, 1.07-1.88; $P<.001)$ more HIT processes. And relative to smaller practices, practices with 3 to 8 physicians used $2.49(95 \% \mathrm{Cl}, 2.26-2.72 ; P<.001)$ more HIT processes. Participation in pay-for-performance programs, participation in public reporting of clinical quality data, and a larger proportion of revenue from Medicare were also associated with greater adoption and use of HIT.

coNCLUSIONS The new Medicare Access and CHIP Reauthorization Act (MACRA) will provide payment incentives and technical support to speed HIT adoption and use by small practices. We found that external incentives were, indeed, positively associated with greater adoption and use of HIT. Our findings also support a strategy of targeting assistance to smaller physician practices and those that are physician owned.

Ann Fam Med 2017;15:56-62. https://doi.org/10.1370/afm.1992.

\section{INTRODUCTION}

I mplementation and use of electronic health records (EHRs) and other health information technology (HIT) has been shown to facilitate primary care practice transformation. ${ }^{1-5}$ The Health Information Technology for Economic and Clinical Health (HITECH) Act of 2009 authorized nearly $\$ 30$ billion to support the increased adoption and use of HIT throughout the US health care delivery system. ${ }^{6}$ In early 2010, the Office of the National Coordinator for Health Information Technology established a nationwide system of regional extension centers to support adoption and use, particularly among small primary care practices. ${ }^{7}$ Beginning in 2011, the Centers for Medicare \& Medicaid Services (CMS) EHR Incentive Program offered financial rewards to practices for implementation and meaningful use of EHRs. ${ }^{8}$ Yet, despite major efforts to expand the adoption and use of HIT, uptake is far from universal. ${ }^{9}$ Understanding the factors that influence HIT adoption and use is critical to inform delivery system reform efforts. 
Recent studies of individual physicians have demonstrated that primary care physicians, and particularly family physicians, are more likely than their colleagues to adopt and use HIT. ${ }^{10,11}$ Repeated cross-sectional studies have also found greater uptake by physicians in larger practices and in practices owned by organizations, compared with physicians in small practices and in practices owned by physicians, respectively. ${ }^{11-13}$ A panel study of physicians conducted in 2011-2012 and 2013 found that persistent nonadopters of HIT were more likely to be employed in solo or 2-physician practices, and less likely to participate in pay-forperformance programs. ${ }^{9}$ Our prior studies in this area have focused on cross-sectional national surveys of physician practices. In an early study of practices with 20 or more physicians, we found greater use of HIT to be associated with larger size, pay-for-performance incentives, and public reporting incentives. ${ }^{14}$ Among practices with 1 to 19 physicians, adoption and use of HIT was associated with larger size, primary care specialty, and pay-for-performance incentives..$^{15}$

This study relies on a unique national longitudinal panel survey with data collection at 2 key time periods (2007-2010 and 2012-2013) to identify practice characteristics and incentives associated with adoption and use of HIT among small primary care practices over time. On the basis of prior research, ${ }^{14}$ we hypothesize that practices are more likely to adopt and use HIT to the extent that they have external incentives for change and internal capabilities to respond to those incentives. The published literature suggests that relevant internal practice capabilities include larger practice size and ownership by a hospital or health care system. External incentives include participation in public reporting of clinical quality, participation in pay-for-performance programs, and the proportion of the practices' revenue obtained from Medicare, a proxy for exposure to the CMS Medicare EHR Incentive Program. ${ }^{8}$

\section{METHODS}

\section{Data Sources and Study Sample}

We conducted 2 national surveys of physician practices, the National Study of Small and Medium-Sized Physician Practices (NSSMPP) and the Third National Study of Physician Organizations (NSPO3) in 20072010 and 2012-2013, respectively. For each study, 40 -minute telephone interviews were conducted with the lead physician or administrator in each organization in nationally representative samples of physician practices and medical groups. The surveys focused on physician practices treating patients with 4 major chronic illnesses: asthma, coronary heart disease, depression, and diabetes. Only organizations with a sizable proportion of primary care physicians (family physicians, general internists, and general practitioners), cardiologists, endocrinologists, or pulmonologists, or some combination thereof, were eligible to participate. We excluded academic faculty practices and practices associated with federal hospitals.

The practices for both studies were sampled from the IMS Healthcare Organization Services database. ${ }^{16}$ These data are widely accepted and have been used in many studies published in peer-reviewed journals. ${ }^{16-18}$ Using this database and the eligibility criteria described above, we drew a random sample of practices stratified by practice size, specialty mix, and location. Additionally, all practices that responded to earlier surveys involving the Second National Study of Physician Organizations ${ }^{19,20}$ and the NSSMPP21,22 were recontacted to respond to the NSPO3 survey. The NSPO3 sample included 1,931 small to medium-sized practices (1-19 physicians) responding to the NSSMPP We determined longitudinal population ratio-adjusted weights based on sampling probabilities with poststratification adjustments. The weights were trimmed within primary sampling units based on the median plus 3 interquartile range (IQR) to avoid outliers that could adversely affect the results of the variances. ${ }^{23}$

Both survey instruments included identical questions about adoption and meaningful use of HIT. Because this study sought to understand the smallest primary care practices, the analytic sample for this longitudinal cohort study included 566 practices that had 8 or fewer physicians at both time periods, were primary care focused (at least $50 \%$ of physicians were in primary care) at both time periods, and responded to both the NSSMPP and NSPO3 surveys. Community health centers were excluded from this analysis. In this article, we use time 1 (T1) and time 2 (T2) to represent the NSSMPP and NSPO3 surveys, respectively.

\section{Measures}

\section{HIT Adoption and Use}

We chose dependent variables pertaining to adoption and use of a range of HIT functionalities. Specific survey items are listed in the Supplemental Appendix (available online at http://www.annfammed.org/content/15/1/56/suppl/DC1) and included the following: (1) majority of physicians used an EHR with patient medications, problem lists, ambulatory care progress notes, automatic alerts for potential drug interactions, decision support prompts and reminders, and alerts for abnormal tests $s_{i}(2)$ the EHR was used to collect data for quality measures; (3) most physicians had electronic access to laboratory results, filled prescriptions, and clinical information regarding emergency department visits and hospital discharge ${ }_{i}(4)$ most physicians used 
electronic transmission of prescriptions to pharmacies (e-prescribing) $)_{i}(5)$ patients had online access to the $\mathrm{EHR}_{i}$ (6) most physicians used e-mail communication with patients; and (7) electronic registries were used for patients with chronic illnesses including diabetes, asthma, congestive heart failure, and depression. Consistent with prior research, ${ }^{14,15}$ we created a HIT summary index (a continuous variable with possible scores ranging from 0 to 18 ) for each practice equal to the count of positive responses to the component questions. The Cronbach $\alpha$ for the HIT index score was 0.87 at T1 and 0.89 at $\mathrm{T} 2$.

\section{External Incentives}

We assessed practices for 3 external incentives promoting HIT adoption and use. The dichotomous public reporting variable was based on whether the practice's data on patient satisfaction and clinical quality were publicly reported. The dichotomous pay-for-performance variable was based on whether the practice had the opportunity to receive additional income from external entities based on their patient satisfaction/clinical quality, use of information technology, efficient use of resources, or some combination thereof. The measure of the proportion of a practices' annual revenue derived from Medicare was designed to serve as a proxy for exposure to the CMS Medicare EHR Incentive Program. ${ }^{8}$ (Practices with few Medicare patients may have been less likely to meet the Meaningful Use criteria by 2014 than practices with most of their patients covered by Medicare, because incentive calculations for eligible clinicians were based on a percentage of Medicare reimbursements.) We defined the Medicare revenue variable as categorical, so that the average HIT at each time could be computed for each of 3 stable categories. For the generalized estimating equations (GEE) regression analysis, the measure was defined as a continuous variable, which has the advantage of using all the available quantitative information about proportion of annual revenue from Medicare, and also reducing the number of parameters in the model.

\section{Organizational Characteristics}

We assessed practices for 2 organizational characteristics. We categorized practice size by number of physicians (1-2 physicians, 3-8 physicians). We measured ownership by whether the practice was owned by a hospital or health system, or health maintenance organization vs physician owned

\section{Statistical Analysis}

For statistical analysis, we first estimated each of the dependent and independent variables at each of the 2 time points and tested for statistical significance of changes over time. Next, we conducted bivariate analysis to examine the relationship between each of the external incentives and organizational characteristics (measured at baseline, T1) and the HIT index score at T1 and T2. To examine the relationship between the HIT index score and the full set of 5 independent variables at both time points, we estimated the coefficients of a linear regression model using a GEE procedure that adjusts the estimates and their standard errors for repeated measurements of the sampled practices.

All analyses were conducted using SAS 9.3 (SAS Institute). The University of California, Berkeley, Committee for the Protection of Human Subjects approved the studies.

\section{RESULTS}

At both T1 and T2, the majority of the cohort was small (1-2 physicians) and physician owned, although there was a slight but significant trend over time toward

\begin{tabular}{|c|c|c|c|}
\hline \multirow[b]{2}{*}{ Variable } & \multicolumn{2}{|c|}{ Practices, \% } & \multirow[b]{2}{*}{$P$ Value } \\
\hline & T1 (2007-2010) & T2 (2012-2013) & \\
\hline \multicolumn{4}{|l|}{ Organizational characteristic } \\
\hline Ownershipa & & & $<.001$ \\
\hline Physician owned & 90.6 & 86.8 & \\
\hline Hospital owned & 9.4 & 13.3 & \\
\hline Size $^{a}$ & & & $<.001$ \\
\hline 1-2 physicians & 65.7 & 63.6 & \\
\hline 3-8 physicians & 34.3 & 36.4 & \\
\hline \multicolumn{4}{|l|}{ External incentive } \\
\hline Pay for performance ${ }^{a}$ & & & $<.001$ \\
\hline No & 47.5 & 41.0 & \\
\hline Yes & 52.5 & 59.0 & \\
\hline Public reporting ${ }^{\text {a }}$ & & & $<.001$ \\
\hline No & 59.2 & 45.4 & \\
\hline Yes & 40.8 & 54.6 & \\
\hline $\begin{array}{l}\text { Percentage of revenue from } \\
\text { Medicare }^{\mathrm{b}}\end{array}$ & & & $<.001$ \\
\hline$\leq 20 \%$ & 28.4 & 24.7 & \\
\hline $21 \%$ to $35 \%$ & 26.6 & 28.4 & \\
\hline$>35 \%$ & 44.9 & 46.9 & \\
\hline \multicolumn{4}{|l|}{$\mathrm{T} 1=$ time $1 ; \mathrm{T} 2=$ time 2.} \\
\hline \multicolumn{4}{|c|}{$\begin{array}{l}{ }^{\mathrm{a}} \text { The McNemar test was used to test for significant differences over time. } \\
{ }^{\mathrm{b}} \text { The Rao-Scott } \chi^{2} \text { test was used to test for a significant difference over time. }\end{array}$} \\
\hline \multicolumn{4}{|c|}{ Note: Analyses were weighted to be nationally representative. } \\
\hline
\end{tabular}


larger size and hospital ownership (Table 1). Participation in public reporting of quality data and pay-forperformance programs both increased significantly over the study period, as did the share of practices obtaining more than 35\% of their revenue from Medicare. The proportion reporting that they did not have an EHR and that they used all paper medical records declined from $66.8 \%$ at $\mathrm{T} 1$ to $32.3 \%$ at T2 (Figure 1 ).

Most measures of HIT adoption and use increased significantly between $\mathrm{T} 1$ and T2, particularly physician use of various EHR functionalities (Table 2). Use of the EHR to collect clinical quality data increased from $17 \%$ to $42 \%$ of the cohort practices $(P<.001)$. Use of patient-oriented functionalities, including patient access to their online medical record and use of e-mail to communicate with patients, also rose significantly, to roughly 1 in 5 practices by T2. Similarly, e-prescribing became much more prevalent over the study period, increasing from $25 \%$ to $70 \%(P<.001)$. Diabetes and asthma registries increased significantly as well, but still, only a minority of primary care practices had adopted them at T2. Adoption of chronic illness registries for congestive heart failure and depression was low at base-
Figure 1. Proportion of practices reporting EHR use at time 1 and time $2(\mathrm{~N}=566)$.

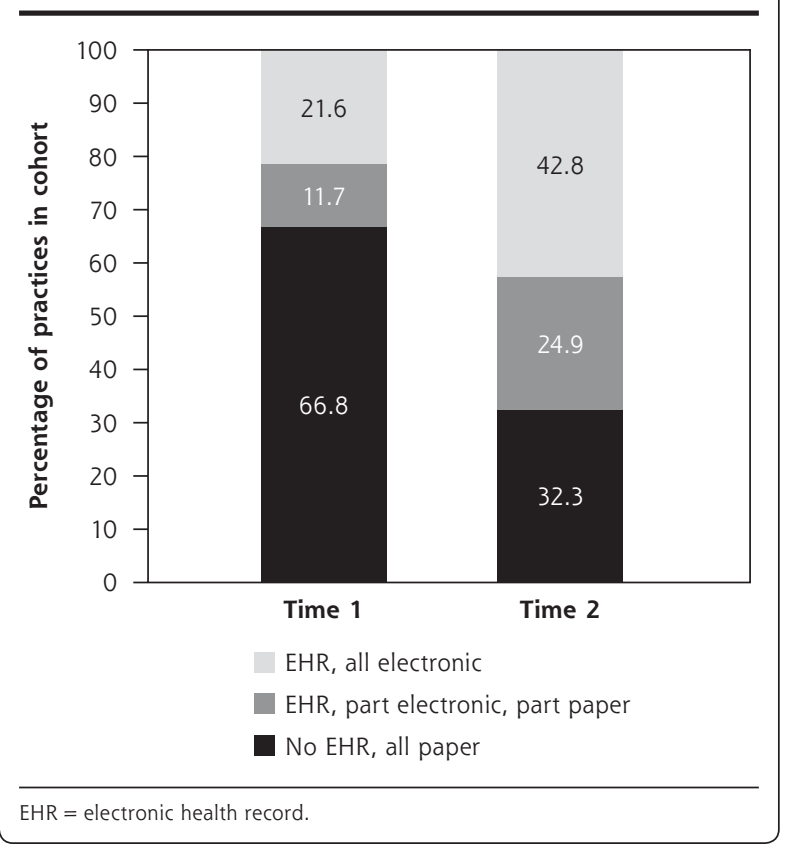

Table 2. Practices' HIT Index Score, and Adoption and Use of Individual HIT Functionalities, Time 1 (2007-2010) and Time 2 (2012-2013)

\begin{tabular}{|c|c|c|c|c|}
\hline Variable & T1 & T2 & $\begin{array}{c}\text { Difference, } \\
\text { T2-T1 }\end{array}$ & $P$ Value ${ }^{a}$ \\
\hline HIT index score, ${ }^{b}$ mean $(95 \% \mathrm{CI})$ & 4.7 & 7.3 & $\begin{array}{c}2.6 \\
(2.3-2.9)\end{array}$ & $<.001$ \\
\hline \multicolumn{5}{|l|}{ HIT functionality } \\
\hline EHR includes patient medications, \% & 29 & 51 & 22 & $<.001$ \\
\hline Physicians use EHR for problem list, \% & 28 & 47 & 21 & $<.001$ \\
\hline Physicians use EHR for potential drug interactions, \% & 17 & 46 & 28 & $<.001$ \\
\hline Physicians use EHR for prompts and reminders, \% & 19 & 34 & 15 & $<.001$ \\
\hline Physicians use EHR for alerts on abnormal test results, \% & 15 & 30 & 15 & $<.001$ \\
\hline Practice uses EHR to collect data for quality measures, \% & 17 & 42 & 26 & $<.001$ \\
\hline Physicians transmit prescriptions directly to pharmacies via computer, \% & 25 & 70 & 45 & $<.001$ \\
\hline Physicians have electronic access to clinical information on patients' ED visits, \% & 70 & 66 & -4 & $<.001$ \\
\hline Physicians have electronic access to hospital discharge summaries, \% & 69 & 73 & 4 & $<.001$ \\
\hline Physicians have electronic access to pharmacy record of prescriptions filled by patients, \% & 21 & 43 & 22 & $<.001$ \\
\hline Physicians communicate with patients via e-mail, \% & 11 & 21 & 10 & $<.001$ \\
\hline Patients can view medical record online, \% & 1 & 19 & 18 & $<.001$ \\
\hline \multicolumn{5}{|l|}{ Practice maintains electronic registry, \% } \\
\hline For patients with asthma & 7 & 17 & 10 & $<.001$ \\
\hline For patients with congestive heart failure & 6 & 9 & 3 & $<.001$ \\
\hline For patients with depression & 6 & 8 & 1 & $<.001$ \\
\hline For patients with diabetes & 12 & 22 & 10 & $<.001$ \\
\hline
\end{tabular}

$\mathrm{ED}=$ emergency department; $\mathrm{EHR}=$ electronic health record; $\mathrm{HIT}=$ health information technology; $\mathrm{T} 1=$ time $1 ; \mathrm{T} 2=$ time 2.

a Paired $t$ tests were used to test for significant difference in the overall HIT index over time. The McNemar test was used to test for significant differences in the proportion adopting each functionality over time.

${ }^{b}$ Possible range is 0 to 18 .

Note: Data were weighted to be nationally representative. 
line $(6 \%)$ and remained relatively static over time. Electronic access to laboratory results and to clinical data from emergency department visits, although highly prevalent at baseline, declined slightly over time.

Practices that were larger at baseline (T1) and practices that were hospital owned at baseline had higher HIT index scores at both T1 and T2 (Table 3). Practices eligible for pay-for-performance incentives at baseline had higher scores at both time points, compared with those not participating in these incentives. Practices that publicly reported quality data at T1 had smaller increases in their HIT scores than those not engaging in this activity, and had relatively lower HIT index scores at $\mathrm{T} 2$.

Table 4 shows the results of our linear regression analysis with GEE, using the HIT index score (with a possible range of $0-18$ ) as the dependent variable and the 5 factors we hypothesized would be independently associated with the score. Hospital-owned practices had a HIT index score that was, on average, 1.48 (95\% $\left.\mathrm{CI}, 1.07-1.88_{i} P<.001\right)$ points higher than physicianowned practices, while practices with 3 to 8 physicians had a score that was, on average, $2.49(95 \% \mathrm{CI}$, 2.26-2.72; $P<.001)$ points higher than that of smaller

Table 3. Bivariate Relationships Between Practice Organizational Characteristics and External Incentives at T1 and Change in the HIT Index Score Over Time

\begin{tabular}{|c|c|c|c|c|}
\hline \multirow[b]{2}{*}{ Variable at $\mathrm{T} 1$} & \multicolumn{2}{|c|}{$\begin{array}{l}\text { HIT Index Score, } \\
\text { Mean (SE) }\end{array}$} & \multirow{2}{*}{$\begin{array}{c}\text { Difference, } \\
\text { T2 - T1, } \\
(95 \% \mathrm{Cl})\end{array}$} & \multirow[b]{2}{*}{$P$ Value } \\
\hline & T1 & T2 & & \\
\hline \multicolumn{5}{|c|}{ Organizational characteristic } \\
\hline \multicolumn{5}{|c|}{ Ownership } \\
\hline Physician owned & $4.63(0.03)$ & $7.24(0.14)$ & $2.61(2.35-2.87)$ & $<.001$ \\
\hline Hospital owned & $6.22(0.22)$ & $8.83(0.70)$ & $2.62(1.53-3.70)$ & $<.001$ \\
\hline \multicolumn{5}{|l|}{ Practice size } \\
\hline 1-2 physicians & $3.88(0.09)$ & $6.35(0.19)$ & $2.47(2.24-2.69)$ & $<.001$ \\
\hline 3-8 physicians & $6.55(0.09)$ & $9.48(0.14)$ & $2.93(2.46-3.39)$ & $<.001$ \\
\hline \multicolumn{5}{|l|}{ External incentive } \\
\hline \multicolumn{5}{|l|}{ Pay for performance } \\
\hline No & $4.49(0.02)$ & $6.89(0.09)$ & $2.39(2.21-2.58)$ & $<.001$ \\
\hline Yes & $5.01(0.08)$ & $7.93(0.27)$ & $2.92(2.50-3.34)$ & $<.001$ \\
\hline \multicolumn{5}{|l|}{ Public reporting } \\
\hline No & $4.63(0.02)$ & $7.57(0.08)$ & $2.94(2.75-3.13)$ & $<.001$ \\
\hline Yes & $4.85(0.12)$ & $6.78(0.39)$ & $1.94(1.36-2.51)$ & $<.001$ \\
\hline \multicolumn{5}{|c|}{$\begin{array}{l}\text { Percentage of revenue from } \\
\text { Medicare }\end{array}$} \\
\hline$\leq 20 \%$ & $5.56(0.08)$ & $7.85(0.16)$ & $2.29(1.85-2.74)$ & $<.001$ \\
\hline $21 \%$ to $35 \%$ & $4.87(0.04)$ & $7.91(0.10)$ & $3.03(2.85-3.22)$ & $<.001$ \\
\hline$>35 \%$ & $4.06(0.07)$ & $6.62(0.21)$ & $2.56(2.28-2.84)$ & $<.001$ \\
\hline \multicolumn{5}{|c|}{$\mathrm{HIT}=$ health information technology; $\mathrm{SE}=$ standard error; $\mathrm{T} 1=$ time $1 ; \mathrm{T} 2=$ time 2.} \\
\hline \multicolumn{5}{|c|}{$\begin{array}{l}\text { Note: Data were weighted to be nationally representative. Paired } t \text { tests were used to test for significant } \\
\text { differences over time. }\end{array}$} \\
\hline
\end{tabular}

practices. External incentives (participation in pay-forperformance programs, participation in public reporting of clinical quality data, and greater proportion of revenue from Medicare) were also positively associated with greater adoption and use of HIT, although their effect sizes were smaller. The regression estimates were very similar when time was explicitly introduced as a predictor, which implies that the predictors continue to differentiate practices even when the general upward trend in HIT index scores is factored out (Supplemental Appendix 3, available online at http://www. annfammed.org/content/15/1/56/suppl/DC1).

\section{DISCUSSION}

Our results demonstrate an increase in 16 measures of HIT adoption and use by a nationally representative cohort of 566 small primary care practices between 2007-2010 and 2012-2013. The proportion of practices that relied on paper records dropped precipitously during this period, and functionalities such as e-prescribing, e-mail with patients, and use of an EHR to collect clinical quality data increased substantially. These trends are consistent with published findings from cross-sectional studies using data from surveys of individual physicians. ${ }^{10,11}$

On the basis of prior research, we hypothesized that physician practices would be more likely to adopt and use HIT to the extent that they had both external incentives for change and internal capabilities to respond to those incentives. Controlling for other factors, participation in payfor-performance incentives and participation in public reporting of clinical quality data were associated with greater adoption and use of HIT. A larger proportion of practice revenue from Medicare was also independently associated with greater HIT uptake. This finding supports our hypothesis that practices serving a greater proportion of Medicare beneficiaries were more responsive to the CMS Medicare EHR Incentive Program.

We also examined HIT adoption and use according to organizational size and ownership. Our results show that practices that 
Table 4. Association Between Practice Organizational Characteristics and External Incentives at Both Time 1 and Time 2, and HIT Index Score

\begin{tabular}{|c|c|c|}
\hline Variable & $\begin{array}{l}\text { HIT Index Score } \\
\text { Estimated Regression } \\
\text { Coefficient }(95 \% \mathrm{Cl})\end{array}$ & $P$ Value \\
\hline \multicolumn{3}{|l|}{ Organizational characteristic } \\
\hline \multicolumn{3}{|l|}{ Ownership } \\
\hline Physician owned & - & \\
\hline Hospital owned & $1.48(1.07-1.88)$ & $<.001$ \\
\hline \multicolumn{3}{|l|}{ Practice size } \\
\hline 1-2 physicians & - & \\
\hline 3-8 physicians & $2.49(2.26-2.72)$ & $<.001$ \\
\hline \multicolumn{3}{|l|}{ External incentive } \\
\hline \multicolumn{3}{|l|}{ Pay for performance } \\
\hline No & - & \\
\hline Yes & $0.47(0.26-0.68)$ & $<.001$ \\
\hline \multicolumn{3}{|l|}{ Public reporting } \\
\hline No & - & \\
\hline Yes & $1.30(1.17-1.43)$ & $<.001$ \\
\hline Percentage of revenue from Medicare & $0.01(0.01-0.02)$ & $<.001$ \\
\hline \multicolumn{3}{|c|}{$\mathrm{GEE}=$ generalized estimating equations; HIT = health information technology. } \\
\hline \multicolumn{3}{|c|}{$\begin{array}{l}\text { Notes: Linear regression model using GEE procedure. Data were weighted to be nationally } \\
\text { representative. GEE analyses performed using SAS version } 9.3 \text { GENMOD procedure. The GEE } \\
\text { model fits } 2 \text { cross-sectional regressions for times } 1 \text { and } 2 \text { with common regression coefficients } \\
\text { and adjustment for the nesting of HIT measurements within practices. }\end{array}$} \\
\hline
\end{tabular}

important unmeasured differences exist. The application of poststratification weights helped in adjusting for nonresponse bias in practice size and specialty composition..$^{23,26}$ Third, our measures of HIT, although comprehensive and representative of the HITECH meaningful use criteria, were not exhaustive. Fourth, we do not have a direct measure of the level of technologic support available to practices for implementation and meaningful use of HIT. ${ }^{18}$ Larger practice size and hospital ownership may serve as partial proxies for availability of these resources, however. Fifth, our analysis does not allow us to test whether changes in the independent variables-for example, changes in practice size, ownership, or external incentives-were associated with changes in the HIT index score; we can simply conclude that, across both $\mathrm{T} 1$ and $\mathrm{T} 2$, certain practice characteristics, such as larger size or hospital ownership, were associated with higher scores.

The majority of primary care practices in the United States are small, and many have taken on the enormous challenge of transforming how they deliver care. Implementation and meaningful use of HIT serves

were larger and those that were owned by hospitals had the highest HIT index scores at T1 and T2.

Despite the substantial increases in adoption and use of HIT, we identified ample room for improvement at T2. Fewer than $50 \%$ of practices used most EHR functionalities, and only 1 in 5 practices used e-mail with patients or allowed patients to see their medical record online. Maintenance of electronic registries for the management of chronic disease was also low for all practices. Chronic disease registries are complex care management tools that are useful for the patientcentered medical home model of primary care, but ones for which practices are typically not directly incentivized (eg, through the CMS Medicare EHR Incentive Program). One study of patient-centered medical home practices in Michigan found that patient registries in those practices were more prevalent than in our national cohort of small primary care practices. ${ }^{24}$

This study has several limitations. First, both the NSSMPP and NSPO3 surveys were conducted with 1 respondent per practice. Respondents, however, were practice leaders who were the most knowledgeable of clinical processes. Second, the 2 surveys had response rates of $63.3 \%$ and $49.7 \%$, respectively. Overall, small differences were found between responding and nonresponding practices in regard to practice size, specialty, and geographic region, ${ }^{25}$ although it is possible that as an important aspect of practice transformation and a foundational element for high-performing primary care. ${ }^{27}$ This tenet remains true even as major policy changes are on the horizon. The Medicare Access and CHIP Reauthorization Act (MACRA) was signed into law in April 2015 and is scheduled to go into effect in 2019. MACRA repealed the Sustainable Growth Rate payment method used by CMS, and will replace the CMS Medicare EHR Incentive Program with new systems of payment based in part on meaningful use of HIT and on clinical practice improvements. The law also allocates $\$ 100$ million to support organizations (eg, quality improvement organizations, regional extension centers) that provide technical assistance to small practices participating in these new systems of payment. Little is known about how exactly these new payment systems will shape up, but our study findings demonstrate that both practice characteristics and external incentives for change are important correlates of HIT adoption and use over time.

To read or post commentaries in response to this article, see it online at http://www.annfammed.org/content/15/1/56.

Key words: health information technology; primary care; physician practice; practice-based research

Submitted November 23, 2015; submitted, revised, June 21, 2016; accepted July 5, 2016. 
Funding support: The National Study of Small and Medium-Sized Physician Practices and the National Study of Physician Organizations III were funded by the Robert Wood Johnson Foundation (awards nos. 35305,68847 , and 71110).

Disclaimer: The statements, findings, conclusions, views, and opinions contained and expressed in this article are based in part on data obtained under license from the following IMS Health information service(s): Healthcare Organizational Services (2007) IMS Health Incorporated. All rights reserved. The statements, findings, conclusions, views, and opinions contained and expressed herein are not necessarily those of IMS Health Incorporated or any of its affiliated or subsidiary entities.

Acknowledgments: We wish to acknowledge James A. Wiley, PhD.

Supplementary materials: Available at http://www.AnnFamMed. org/content/15/1/56/suppl/DC1/.

\section{References}

1. Davis K, Schoenbaum SC, Audet AM. A 2020 vision of patientcentered primary care. J Gen Intern Med. 2005;20(10):953-957.

2. Rittenhouse DR, Shortell SM. The patient-centered medical home: will it stand the test of health reform? JAMA. 2009;301(19): 2038-2040.

3. Kraschnewski JL, Gabbay RA. Role of health information technologies in the Patient-Centered Medical Home. J Diabetes Sci Technol. 2013;7(5):1376-1385.

4. Scholle SH, Asche SE, Morton S, Solberg LI, Tirodkar MA, Jaén CR. Support and strategies for change among small patient-centered medical home practices. Ann Fam Med. 2013;11(Suppl 1):S6-S13.

5. Finkelstein J, Barr MS, Kothari PP, Nace DK, Quinn M. Patientcentered medical home cyberinfrastructure current and future landscape. Am J Prev Med. 2011;40(5)(Suppl 2):S225-S233.

6. American Recovery and Reinvestment Act, Pub L No. 111-5, Stat 123, 2009.

7. Maxson E, Jain S, Kendall M, Mostashari F, Blumenthal D. The regional extension center program: helping physicians meaningfully use health information technology. Ann Intern Med. 2010;153(10): 666-670.

8. Centers for Medicare \& Medicaid Services. Electronic health records incentive programs. CMS Web site. https://www.cms.gov/ Regulations-and-Guidance/Legislation/EHRIncentivePrograms/index. html. Updated Sep 2, 2016. Accessed Nov 9, 2015.

9. DesRoches C. Progress and challenges in electronic health record adoption: findings from a national survey of physicians. Ann Intern Med. 2015;162(5):396.

10. Xierali IM, Hsiao CJ, Puffer JC, et al. The rise of electronic health record adoption among family physicians. Ann Fam Med. 2013;11(1): 14-19.

11. Furukawa MF, King J, Patel V, Hsiao CJ, Adler-Milstein J, Jha AK. Despite substantial progress In EHR adoption, health information exchange and patient engagement remain low in office settings. Health Aff (Millwood). 2014;33(9):1672-1679.
12. Decker SL, Jamoom EW, Sisk JE. Physicians in nonprimary care and small practices and those age 55 and older lag in adopting electronic health record systems. Health Aff (Millwood). 2012;31(5): 1108-1114.

13. Hsiao CJ, Jha AK, King J, Patel V, Furukawa MF, Mostashari F. Office-based physicians are responding to incentives and assistance by adopting and using electronic health records. Health Aff (Millwood). 2013;32(8):1470-1477.

14. Robinson JC, Casalino LP, Gillies RR, Rittenhouse DR, Shortell SS, Fernandes-Taylor $S$. Financial incentives, quality improvement programs, and the adoption of clinical information technology. Med Care. 2009;47(4):411-417.

15. McClellan SR, Casalino LP, Shortell SM, Rittenhouse DR. When does adoption of health information technology by physician practices lead to use by physicians within the practice? J Am Med Inform Assoc. 2013;20(e1):e26-e32.

16. Health IMS. IMS Health Web site. http://www.imshealth.com/portal/site/imshealth. Accessed Nov 9, 2015.

17. Nyweide DJ, Weeks WB, Gottlieb DJ, Casalino LP, Fisher ES. Relationship of primary care physicians' patient caseload with measurement of quality and cost performance. JAMA. 2009;302(22): 2444-2450.

18. Ryan AM, Bishop TF, Shih S, Casalino LP. Small physician practices in New York needed sustained help to realize gains in quality from use of electronic health records. Health Aff (Millwood). 2013;32(1): 53-62.

19. Shortell SM, Gillies R, Siddique J, et al. Improving chronic illness care: a longitudinal cohort analysis of large physician organizations. Med Care. 2009;47(9):932-939.

20. Rittenhouse DR, Casalino LP, Gillies RR, Shortell SM, Lau B. Measuring the medical home infrastructure in large medical groups. Health Aff (Millwood). 2008;27(5):1246-1258.

21. Casalino LP, Rittenhouse DR, Gillies RR, Shortell SM. Specialist physician practices as patient-centered medical homes. $N$ Engl J Med. 2010;362(17):1555-1558.

22. Rittenhouse DR, Casalino LP, Shortell SM, et al. Small and mediumsize physician practices use few patient-centered medical home processes. Health Aff (Millwood). 2011;30(8):1575-1584.

23. Little RJ. Post-stratification: a modeler's perspective. J Am Stat Assoc. 1993;88(423):1001-1012.

24. Adler-Milstein J, Cohen GR. Implementing the IT infrastructure for health reform: adoption of health IT among patient-centered medical home practices. AMIA Annu Symp Proc. 2013;2013:11-16.

25. Wiley JA, Rittenhouse DR, Shortell SM, et al. Managing chronic illness: physician practices increased the use of care management and medical home processes. Health Aff (Millwood). 2015;34(1):78-86.

26. Wooldridge JM. Pooling cross sections over time: simple panel methods. In: Wooldridge JM, ed. Introductory Econometrics: A Modern Approach. 2nd ed. Mason, OH: South-Western College Pub; 2002:405-440.

27. Bodenheimer T, Ghorob A, Willard-Grace R, Grumbach K. The 10 building blocks of high-performing primary care. Ann Fam Med. 2014;12(2):166-171. 